Research paper

\title{
Modelling sedimentation-consolidation in the framework of a one-dimensional two-phase flow model
}

JULIEN CHAUCHAT, Associate Professor, Laboratoire des Ecoulements Géophysiques et Industriels, UMR 5519, UJF, INPG, 1023 rue de de la piscine, 38400 Saint Martin d'Hères, France

Email: julien.chauchat@grenoble-inp.fr (author for correspondence)

SYLVAIN GUILLOU (IAHR Member), Associate Professor, Laboratoire Universitaire des Sciences Appliquées de Cherbourg, EA 4253, ESIX Normandie - Université de Caen, BP 78, 50130 Octeville, France

Email: sylvain.guillou@unicaen.fr

DAMIEN PHAM VAN BANG, PhD Engineer, Université Paris-Est, Saint Venant Laboratory for Hydraulics, ENPC, EDF R\&D, CETMEF, 78400 Chatou, France

Email: damien.pham-van-bang@developpement-durable.gouv.fr

KIM DAN NGUYEN, Professor, Université Paris-Est, Saint Venant Laboratory for Hydraulics, ENPC, EDF R\&D, CETMEF, 78400 Chatou, France

Email: dan.nguyen@saint-venant-lab.fr

\begin{abstract}
A one-dimensional vertical two-phase flow model for sedimentation-consolidation process is presented. The model is based on solving the continuity and momentum equations for both fluid and solid phases. In the non-cohesive case, the momentum transfer between the two phases is reduced to the drag force around a single particle modified to take the hindrance effects into account. In the cohesive case, Darcy-Gersevanov's law is used for the closure of the momentum transfer between the two phases and the concept of "effective stress" is introduced to take into account the bed structuring. These closure laws are validated against high resolution experimental data in terms of settling curves and concentration profiles. The reliability of the model is illustrated from an analysis of the momentum balances at different stages during the process. Finally, the proposed closure laws and numerical algorithms are shown to be able to quantitatively reproduce sedimentation of non-cohesive and sedimentationconsolidation of cohesive sediments, including mud.
\end{abstract}

Keywords: Consolidation ; Numerical model ; One-dimensional models ; Sedimentation ; Two-phase flow

\section{Introduction}

Sedimentation and consolidation are important physical processes of the sediment transport in Estuarine and Coastal Zones (ECZs). From a physical point of view, sedimentation is the process of suspended-particles settling whereas consolidation corresponds to the compaction of a soil skeleton under its own weight (Toorman 1996). The latter is specific to cohesive sediment. The former is observed for both non-cohesive and cohesive sediment 
particles though it strongly differs due to the presence of particle-particle interactions and sediment heterogeneity in the cohesive case (flocculation).

When a suspension of cohesive sediment particles settles in quiescent water, its behaviour mainly depends on the sediment concentration. Four different regimes are observed: flocculation, hindered, permeability and effectivestress regimes. The first two correspond to sedimentation and the last two correspond to consolidation (Dankers and Winterwerp 2007). In the present study only the last three regimes are considered. In the hindered regime, corresponding to sediment concentration between three and tens of grams per litter, the presence of neighbouring particles causes the hindrance of suspension settling. The transition between sedimentation and consolidation is characterised by the gel point (Buscall 1990), which usually lies between $30 \mathrm{~g} \mathrm{l}^{-1}$ and $150 \mathrm{~g} \mathrm{l}^{-1}$ (Merckelbach and Kranenburg 2004; Camenen and Pham Van Bang 2011). From this critical concentration, particle-particle interactions increase and a solid skeleton develops inside the sediment bed. Under their own load, sediment-bed aggregates break up and release their water content. From mass conservation, this released water flows upward through the forming solid skeleton and leads to an excess pore pressure (Been and Sills 1981). The fluid flow relative to the porous network leads to an increase of the drag force on the solid particles, that reduces their settling velocity (Toorman 1999). This is the permeability regime. The excess pore pressure slowly dissipates as the cohesive sediment bed is compacting. When the excess pore pressure has fully dissipated, the solid skeleton is well developed and supports the apparent sediment's weight (Been and Sills 1981). The slow settling observed in this regime is due to the compression of the solid skeleton under its own weight that corresponds to the effective stress regime.

In the case of a suspension of non-cohesive particles only two regimes are observed. The first one corresponds to the hindered settling regime where particles settle to the bed with a settling velocity that depends on the local particles concentration i.e. hindrance effect (Richardson and Zaki 1954). When the particles concentration reaches a given percolation value, that corresponds to the loose packing fraction, the particles form a loose bed.

In classical sediment transport models for ECZs the suspended sediment is viewed as a passive scalar, for which an advection-diffusion equation is solved. Sedimentation is therefore modelled by introducing a settling velocity that is parameterised to account for the flocculation and hindered regimes. The computational domain in these models is bounded by a fictive bed, which is usually defined for the solid concentration exceeding about $100 \mathrm{~g} \mathrm{l}^{-1}$. Below the fictive bed, extra models for solid-particle Consolidating and Settling Bed (CSB) are introduced (e.g. Gibson et al. (1967)'s equation). The main limitation in these models comes from the need to prescribe empirical relationships for both erosion and deposition flux between the two models (suspended-sediment transport model and CSB) (Teisson 1991; Thiébot et al. 2011). In the two-phase approach, continuity and momentum equations are derived for each phase, fluid or solid, with the introduction of interaction terms between the two phases. The two-phase approach has been applied to the modelling of sediment-transport problems since the 80s (Drew (1983); Teisson et al. (1992); Le Hir (1994); Greimann et al. (1999), amongst others). More recently, the interest in this approach has increased and led to numerous publications mainly for non-cohesive sediment transport, i.e. sand (Barbry et al. (2000); Greimann and Holly (2001); Dong and Zhang (2002); Hsu et al. (2003); Jiang et al. (2004); Longo (2005); Chauchat and Guillou (2008); Bakhtyar et al. (2009); Jha and Bombardelli (2010), amongst others). These studies show encouraging results concerning the suspended-load and bed-load transport mainly by integrating the influence of the sediment particles on the fluid turbulence and the collisions between particles (two-way and four-way coupling). Concerning sedimentation-consolidation problems, Toorman (1996) has presented a unifying theory derived from the two-phase equations that allows the reconciliation of Kynch's sedimentation theory (Kynch 1952) at low sediment concentration and Gibson's consolidation theory (Gibson et al. 1967) for higher sediment concentration (see Winterwerp and Van Kesteren (2004) for details on these theories). However no direct application to sedimentation-consolidation of the two-phase model has been presented in the literature. Recently, first applications of two-phase model for fine-sediment transport in ECZs have been published (Hsu et al. 2007; Nguyen et al. 2009; Torres-Freyermuth and Hsu 2010; Nguyen et al. 2012). The results obtained in these studies have shown the potential of this modelling approach and also the needs for process oriented studies to determine the adequate closure laws for cohesive sediments. In all these papers the mud sedimentation and consolidation processes were not accounted for although they are essential in the understanding of mud-flow interactions. 
The most valuable validation of a sedimentation-consolidation model is achieved by a comparison of calculated and measured concentration profiles (Toorman 1999). For this purpose recent original experimental data (Pham Van Bang et al. 2008) obtained using Magnetic Resonant Imaging (MRI) technique are used in this paper. This technique allows us to measure concentration profiles at high frequency, even in conditions where initial concentrations are dilute. The aim of this paper is to show the reliability of new developments in the two-phase flow model (Chauchat and Guillou 2008; Nguyen et al. 2009) to simulate sedimentation and consolidation processes of cohesive and non-cohesive sediments based on a comparison with the above mentioned experimental data. The model presented herein is one-dimensional vertical but it can be straightforwardly generalised to multidimensional situations.

\section{Model Formulation}

The present two-phase flow model is based on averaged equations for each phase, fluid and sediment, inspired from the early work presented in Barbry et al. (2000), Chauchat and Guillou (2008) and Nguyen et al. (2009). The averaged equation for mass conservation (1) and momentum conservation (2) for a phase $k$ reads (Drew and Lahey 1993):

$$
\begin{gathered}
\frac{\partial \alpha_{k} \rho_{k}}{\partial t}+\nabla \cdot\left(\alpha_{k} \rho_{k} u_{k}\right)=\frac{\mathrm{D} \alpha_{k} \rho_{k}}{\mathrm{D} t}=0, \\
\frac{\mathrm{D} \alpha_{k} \rho_{k} u_{k}}{\mathrm{D} t}=\nabla \cdot\left(-\alpha_{k} p_{k} \mathbf{I}+\alpha_{k} \tau_{\mathbf{k}}\right)+\alpha_{k} \rho_{k} g+M_{k},
\end{gathered}
$$

where the subscript $k$ can be either $f$ for the fluid phase or $s$ for the solid phase. In these two equations $\alpha_{k}$, $u_{k}, \rho_{k}$ are the volume fraction, the velocity vector and the density of phase $k ; p_{k}$ is the pressure of phase $k ; \mathbf{I}$ the identity tensor ; $\tau_{\mathbf{k}}$ the deviatoric part of the viscous stress tensor of phase $k ; g$ is the acceleration due to gravity $; M_{k}$ is the interfacial momentum transfer between fluid and solid phases.

To be consistent with Jackson (2000)'s two-phase equations we assume that the shear stresses of the fluid and solid phases $\tau_{\mathbf{f}}$ and $\tau_{\mathbf{s}}$ are equal to the mixture's viscous shear stresses $\tau_{\mathbf{v}}$ expressed as:

$$
\tau_{\mathbf{v}}=\mu_{m i x}\left[\nabla u_{m}+\left(\nabla u_{m}\right)^{T}\right],
$$

where $\mu_{m i x}=\mu_{f}\left(1+\beta \alpha_{s}\right)$ is the mixture viscosity and $\beta$ is the amplification factor for viscosity. As shown by Jackson (2000) for rigid particles, the fluid shear stress should be proportional to the mixture shear rate where $u_{m}=(1-\phi) u_{f}+\phi u_{p}$ is the volume averaged mixture velocity. The parameter $\beta$ accounts for the non-Newtonian characteristics of the flow when the volume fraction of the solid phase reaches high values. The formulation from Graham (1981) is used:

$$
\beta=\frac{5}{2}+\frac{9}{4} \frac{1}{1+\tilde{d}}\left(\frac{1}{2 \tilde{d}}-\frac{1}{1+2 \tilde{d}}-\frac{1}{(1+2 \tilde{d})^{2}}\right) \frac{1}{\alpha_{s}},
$$

where $\tilde{d}$ is the inter-particle distance non-dimensionalised by the particle diameter. From geometrical considerations it is possible to express this ratio as a function of the solid volume fraction: $\tilde{d}=\left[1-\left(\alpha_{s} / \alpha_{s}^{\max }\right)^{1 / 3}\right] /\left(\alpha_{s} / \alpha_{s}^{\max }\right)^{1 / 3}$, where $\alpha_{s}^{\max }$ is the solid volume fraction for maximum packing of spheres. For a simple cubic packing of rigid spheres, this value is $\alpha_{s}^{\max }=0.625$. This formulation is consistent with the expression proposed by Einstein (1906) in the dilute case: $\mu_{m i x}=\mu_{f}\left(1+2.5 \alpha_{s}\right)$ and with the expression proposed by Frankel and Acrivos (1967) for dense suspension: $\mu_{\text {mix }}=\mu_{f} 9 / 8\left[\left(\alpha_{s}^{\max } / \alpha_{s}\right)^{1 / 3}-1\right]^{-1}$.

It is important to keep in mind that only one-dimensional vertical problems are considered here. Therefore, only the normal component of the viscous shear stresses are relevant in the present model and not the tangential ones like for debris flows or bed-load transport where a horizontal motion is considered (Berzi and Jenkins 2008; Chauchat and Médale 2010). In order to deal with such flows, an additional term should be added to the solid phase stress tensor $\tau_{\mathbf{p p}}$, which represents the contribution of particle-particle interactions to the tangential stresses.

The interfacial momentum transfer term is defined following Drew and Lahey (1993) by:

$$
M_{k}=\left(p_{f} \mathbf{I}-\tau_{\mathbf{v}}\right) \cdot \nabla \alpha_{k}+M_{k}^{\prime}
$$


The first term represents the generalised buoyancy composed of two contributions: one is related to the fluid pressure, the so-called Archimedes' buoyancy force and the second corresponds to the local fluid shearing acting on the fluid-particle interfaces. The second term in equation (5) represents all the remaining contributions to the fluid-particle interactions (drag, lift, added mass, Basset forces). Its closure depends both on the properties of the solid particles and the regime of fluid flows around the particles. The specific closures for non-cohesive and cohesive sediment particles will be discussed in the following sections.

The physical meaning of the fluid pressure is the same as for a single phase fluid flow. It represents the resistance of the fluid to compression. For the solid phase pressure, one has to consider the total pressure or the mixture pressure:

$$
\tilde{p}=\alpha_{s} p_{s}+\alpha_{f} p_{f}
$$

that represents the resistance to compression of the mixture. Since there are particles and fluid in the mixture, the resistance to compression has two contributions: one comes from the fluid filling the pores $\left(p_{f}\right)$ and the other is originated from the network of contacts between particles for sufficiently high concentration $\left(\sigma_{e}\right)$. In the present study, $\sigma_{e}$ will be denoted as particle pressure for non-cohesive sediment and effective stress for cohesive ones. This is the effective stress principle as proposed by Terzaghi (1923):

$$
\tilde{p}=p_{f}+\sigma_{e} .
$$

When the solid volume fraction exceeds a percolation value, a solid skeleton appears and the effective stress or particle pressure develops. It should vanish rapidly when $\alpha_{s}$ decreases below this percolation threshold. This percolation value is different in the non-cohesive and cohesive cases, it corresponds to the random loose packing for non-cohesive particles and is denoted as $\alpha_{s}^{*}$, and it is the gelling point $\alpha_{s}^{\text {gel }}$ for cohesive ones.

Identifying equations (6) and (7) the solid phase pressure $p_{s}$ is written as:

$$
p_{s}=p_{f}+\sigma_{e} / \alpha_{s}
$$

in order to respect Terzaghi's principle. This expression is identical to the one proposed by Concha et al. (1996) and Bürger (2000) adapted to our notations. Again the specific closure for $\sigma_{e}$ depends on the nature of the particles: cohesive and deformable particles such as mud, or non-cohesive and "rigid" particles such as sand or beads.

Finally, substituting (5) and (8) in the momentum equations (2) leads to the following one-dimensional two-phase equations:

$$
\begin{gathered}
\alpha_{f}+\alpha_{s}=1, \\
\frac{\partial \alpha_{f} \rho_{f}}{\partial t}+\frac{\partial \alpha_{f} \rho_{f} w_{f}}{\partial z}=0, \\
\frac{\partial \alpha_{s} \rho_{s}}{\partial t}+\frac{\partial \alpha_{s} \rho_{s} w_{s}}{\partial z}=0, \\
\frac{\partial \alpha_{f} \rho_{f} w_{f}}{\partial t}+\frac{\partial \alpha_{f} \rho_{f} w_{f} w_{f}}{\partial z}=-\alpha_{f} \frac{\partial p_{f}}{\partial z}+\alpha_{f} \frac{\partial \tau_{v}^{z z}}{\partial z}-\alpha_{f} \rho_{f} g+M_{f}^{z^{\prime}} \\
\frac{\partial \alpha_{s} \rho_{s} w_{s}}{\partial t}+\frac{\partial \alpha_{s} \rho_{s} w_{s} w_{s}}{\partial z}=-\alpha_{s} \frac{\partial p_{f}}{\partial z}-\frac{\partial \sigma_{e}}{\partial z}+\alpha_{s} \frac{\partial \tau_{v}^{z z}}{\partial z}-\alpha_{s} \rho_{s} g+M_{s}^{z^{\prime}}
\end{gathered}
$$

Equation (9) represents the global volume conservation that gives an additional equation. The system (9)(13) is composed of five equations expressed in terms of the five unknowns $\alpha_{f}, \alpha_{s}, w_{f}, w_{s}$ and $p_{f}$. This system of equations can be solved numerically if the closures for $M_{s}^{\prime z}, M_{f}^{\prime z}$ and $\sigma_{e}$ are given in terms of $\alpha_{f}, \alpha_{s}, w_{f}, w_{s}, p_{f}$.

The set of equations (9)-(13) are solved by a projection method. A finite difference technique is used for the discretisation of momentum conservation equations on a staggered grid. The governing equations are implicitly solved. All the details concerning the algorithm and discretisation are given in appendix A (see online version of the article). 
The present model equations are consistent with those used in Bürger (2000)'s and with Toorman (1996)'s models. The originality of the proposed model is that both fluid phase and solid phase velocities, sediment concentration as well as fluid pressure are solved by the model whereas Bürger (2000)'s and Toorman (1996)'s models only solve for the sediment concentration and deduce the excess pore pressure from a simplified momentum balance for the fluid phase. The present model formulation is more general and would enable the study of the complex interaction between a sedimenting and/or consolidating suspension with a boundary layer flow.

\section{Sedimentation of non-cohesive particles}

\subsection{Model suspension experiments}

We first validate the present two-phase model for pure sedimentation of non-cohesive particles, then no consolidation occurs. A set of experimental data (Pham Van Bang et al. 2008) has been used for this validation. This concerns a suspension of mono-disperse spherical polystyrene beads of diameter $d=0.29 \pm 0.03 \mathrm{~mm}$, and of density $\rho_{p}=1.05 \mathrm{~kg} \mathrm{~m}^{-3}$ in Rhodorsil silicone oil (viscosity $\mu_{f}=2010^{-3} \mathrm{~Pa} \mathrm{~s}$, density $\rho_{f}=0.95 \mathrm{~kg} \mathrm{~m}^{-3}$ ). The material was prepared in a well-mixed cylindrical container (base diameter $50 \mathrm{~mm}$; height $100 \mathrm{~mm}$ ) for an initial solid volume fraction $\left(\alpha_{s}^{0}=0.48\right)$. The container was covered and placed in a Proton MRI for automatic measurements of the solid concentration profiles along the vertical. Experiments were performed at the Navier Laboratory (Ecole de Ponts ParisTech, Champs-sur-Marne, France) on a Bruker 24/80 DBX MRI facility: the vertical prototype operates at $0.5 \mathrm{~T}(20 \mathrm{MHz}$ proton frequency). The vertical concentration profiles (a measuring point for every $0.9375 \mathrm{~mm}$ on the vertical) were averaged over 16 instantaneous profiles, which were taken every 3 seconds. Thus one single-profile was obtained for every 60 seconds.

\subsection{Closures for non-cohesive spherical particles}

The closure laws for the momentum transfer term $M_{k}^{z^{\prime}}$ and the particle pressure $\sigma_{e}$ are needed. For the present experimental configuration (polystyrene beads in silicon oil) the particulate Reynolds number $\operatorname{Re}_{\mathrm{p}}=\rho_{f} \alpha_{f} d \|$ $w_{s}-w_{f} \| / \mu_{f}$ is at the order of magnitude about $10^{-3}-10^{-4}$, and then $M_{k}^{\prime}$ reduces to the Stokes drag:

$$
M_{s}^{z^{\prime}}=-M_{f}^{z^{\prime}}=\frac{3 \alpha_{s} \rho_{f}}{4 d} C_{D}\left\|w_{s}-w_{f}\right\|\left(w_{s}-w_{f}\right) \alpha_{f}^{2-n_{R Z}}
$$

where $C_{D}$ is the averaged drag coefficient for a single particle (Stokes drag coefficient): $C_{D}=24 / \operatorname{Re}_{\mathrm{p}}$ for small particulate Reynolds number; and the term $\alpha_{f}^{2-n_{R Z}}$ is the hindrance function proposed by Richardson and Zaki (1954). $n_{R Z}$ is an empirical coefficient that allows to account for the decrease of the particle settling velocity when the local concentration of particles increases Nicolai et al. (1995) have obtained a value of the Richardson and Zaki exponent $n_{R Z}=5 \pm 0.3$ for the sedimentation of mono-disperse spherical particles at small particulate Reynolds number $\left(\operatorname{Re}_{\mathrm{p}} \leq 10^{-3}\right)$ which corresponds to the present experimental conditions.

Following Hsu et al. (2004) we model the particulate pressure (solid phase normal stresses) due to enduring contact using a Hertz contact model. They proposed the following relationship:

$$
\sigma_{e}=\left\{\begin{array}{lll}
0 & \text { if } \quad \alpha_{s}<\alpha_{s}^{*} \\
\Sigma\left(\alpha_{s}\right)\left(\alpha_{s}-\alpha_{s}^{*}\right)^{\xi} & \text { if } \quad \alpha_{s}^{*} \leq \alpha_{s} \leq \alpha_{s}^{\max } .
\end{array}\right.
$$

The term $\left(\alpha_{s}-\alpha_{s}^{*}\right)^{\xi}$ represents the average compressive volume strain divided by the particle's diameter. The exponent $\xi$ is an ad-hoc coefficient that must be calibrated. Hsu et al. (2004) have proposed a value of 5.5 from a comparison with experiments. $\Sigma\left(\alpha_{s}\right)$ is a coefficient proportional to the coordination number and depends on the mechanical properties of the material of the particles (i.e. Poisson coefficient $\nu$ and Young modulus $E$ ):

$$
\Sigma\left(\alpha_{s}\right)=\frac{E \alpha_{s}}{9 \pi \sqrt{3}\left(1-\nu^{2}\right)}\left\{3+3 \sin \left[\frac{\pi}{2}\left(2 \frac{\alpha_{s}^{*}-\alpha_{s}}{\alpha_{s}^{\text {max }}-\alpha_{s}^{*}}-1\right)\right]\right\}
$$

For polystyrene beads the following values are used $\nu=0, E=310^{9} \mathrm{~Pa}$ and $\xi=4.5$. The value of $\xi$ has been determined by trial and error in order to insure a correct hydrostatic pressure distribution for the solid phase 
at the end of the sedimentation process. Details concerning this calibration are given in Appendix B (See online version of the article). For a suspension of monodisperse spherical particles, the random loose packing is about $\alpha_{s}^{*}=0.57$ and the maximum packing is about $\alpha_{s}^{\max }=0.6$.

\subsection{Results and discussion}

In the numerical simulation we use a uniform 300-nodes mesh $\left(\Delta z=3.310^{-4} \mathrm{~m}\right)$ and a time step of $\Delta t=5.10^{-5} \mathrm{~s}$. The Richardson-Zaki exponent $n_{R Z}$ is set to 5.15 after calibration, this value is consistent with the one given by Nicolai et al. (1995). The initial and boundary conditions are imposed as described in Fig. 1. As initial condition, the solid phase volume fraction is constant and equal to $\alpha_{s}^{0}$ below $Z_{i}^{0}$ and zero above, the solid phase vertical velocity is calculated from a simplified balance equation between gravity and drag force, using relationship (14) and the fluid phase velocity is initialised to ensure incompressibility of the mixture. At the top and bottom boundaries, the vertical velocities vanish and the normal derivative of the volume fraction are taken equal to zero.

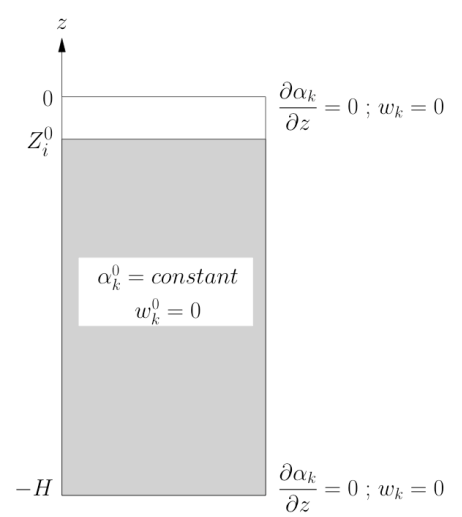

Figure 1: Sketch of the numerical configuration with initial and boundary conditions for the numerical model

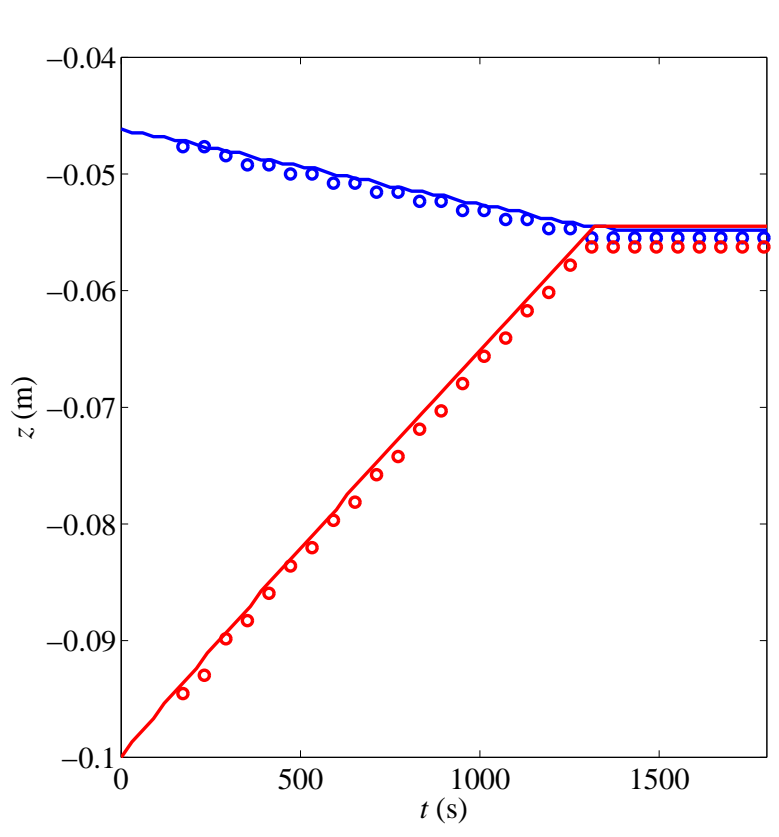

(a)
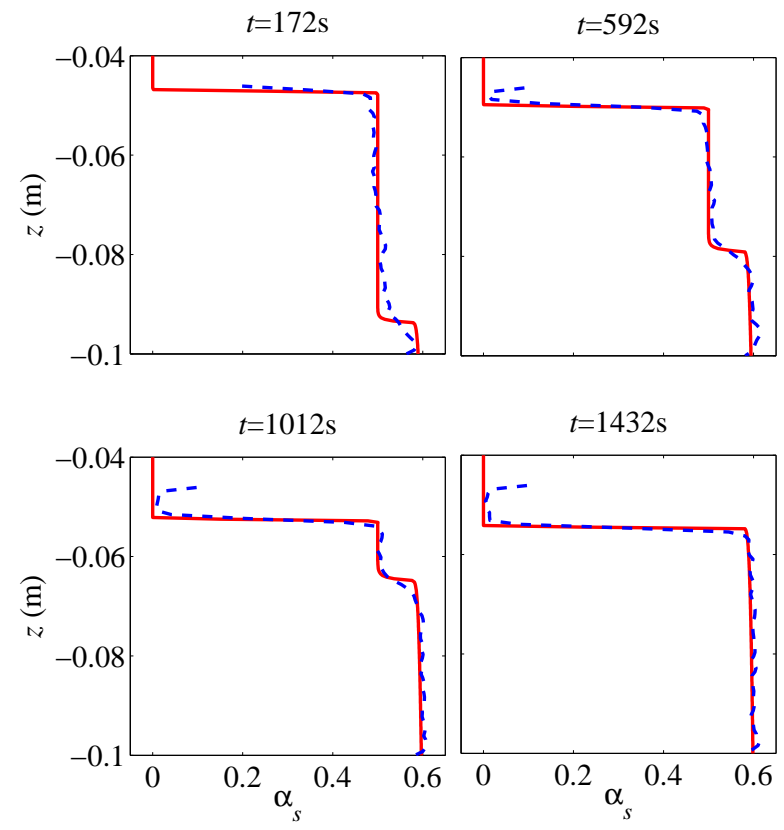

(b)

Figure 2: Comparison of two-phase numerical results with experiments of Pham Van Bang et al. (2008) a) Settling curves: time evolution of the lower and upper interface positions (circles: experiments ; lines: model) and b) Profiles of solid volume fraction (dashed blue lines: experiment ; solid red lines: model). 

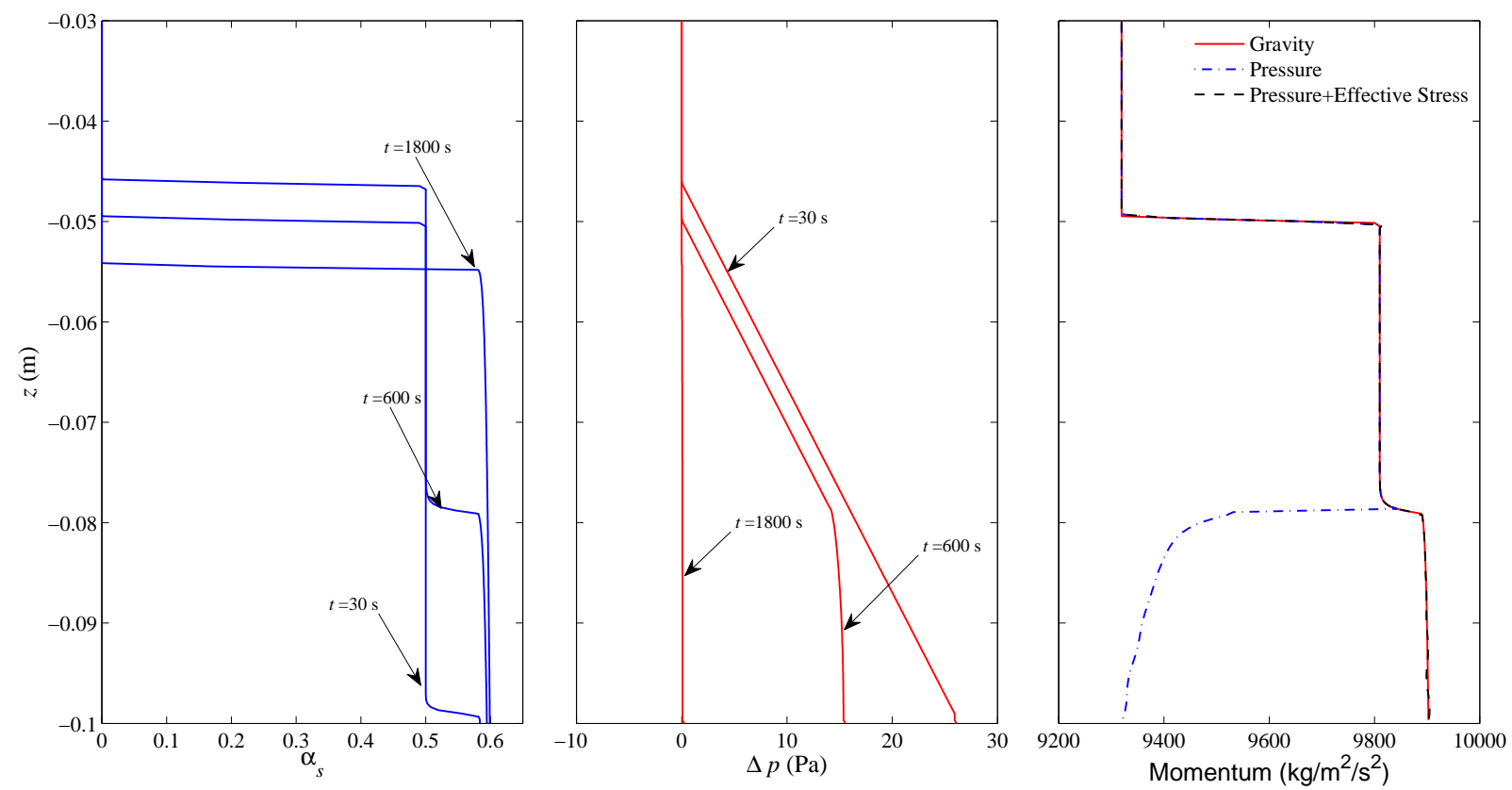

Figure 3: Vertical profiles of solid volume fraction (left), excess pore pressure: $\Delta p=p_{f}-\left[p_{a t m}-\rho_{f} g z\right]$ (middle) and vertical mixture momentum balance at $t=600 \mathrm{~s}$ (see equation (17)) (right). The red solid line $(-)$ represents the gravity force, the blue dash-dotted line (-.-) represents the fluid pressure force and the dashed black line (- -) represents the sum of the pressure and effective stress forces in equation (17).

The convergence of the numerical results in terms of the grid size and the time step has been checked. The results of the sensitivity analysis are given in appendix B (see online version of the article). A minimum grid size of $\Delta z=10^{-3} \mathrm{~m}$ and minimum time step of $\Delta t=10^{-3} \mathrm{~s}$ is required to satisfactorily represent the fluid-bed interface.

Figure 2 shows the settling curves for both experiments and numerical simulation in the left panel (a), time evolution of the fluid-suspension and suspension-fixed bed interfaces, and the concentration profiles at different stages during the process on the right panels (b). In Fig. 2(a) the upper interface corresponds to the interface between the clear fluid and the suspension $Z_{i}^{u p}$. The lower one denotes the interface between the suspension and the granular bed at maximum packing fraction $Z_{i}^{\text {low }}$. They are defined as follows: $Z_{i}^{u p}=\max \left\{z \mid \alpha_{s} \geq \alpha_{s}^{0}\right\}$ and $Z_{i}^{\text {low }}=\max \left\{z \mid \alpha_{s} \geq 0.5\left(\alpha_{s}^{\max }+\alpha_{s}^{0}\right)\right\}$. After roughly $1200 \mathrm{~s}$, the interfaces match and stabilise to a constant value. The bed is at rest and the concentration of the suspension has reach the maximum packing fraction $\alpha_{s}^{\max }$ as shown in Fig. 2(b) at $\mathrm{t}=1432 \mathrm{~s}$. Figure 2 shows that the numerical and experimental time evolution of the interface positions and vertical profiles of solid volume fraction at different times are in good agreement. This validates the closure laws (14) and (15) as well as the numerical model presented in section 2. The increase of the measured solid volume fraction observed above the upper interface is due to an artefact in the MRI measurements.

Figure 3 shows (from left to right) the solid volume fraction profiles, the excess pore pressure and the vertical momentum balance of the mixture at various times during sedimentation $(\mathrm{t}=30,600$ and $1800 \mathrm{~s})$. The vertical momentum balance for the mixture is obtained from the sum of the momentum equations for the fluid phase (12) and the solid phase (13) that reads:

$$
\frac{\partial}{\partial t}\left(\alpha_{s} \rho_{s} w_{s}+\alpha_{f} \rho_{f} w_{f}\right)+\frac{\partial}{\partial z}\left(\alpha_{s} \rho_{s} w_{s}^{2}+\alpha_{f} \rho_{f} w_{f}^{2}\right)=-\frac{\partial p_{f}}{\partial z}-\frac{\partial \sigma_{e}}{\partial z}+\frac{\partial \tau_{m}^{z z}}{\partial z}-\underbrace{\left(\alpha_{s} \rho_{s}+\alpha_{f} \rho_{f}\right)}_{=\rho_{\text {mix }}} g .
$$

When all the particles have settled to the bed (bed at rest), the vertical gradient of fluid pressure is expected to balance the pure fluid's weight while the effective stress balances the apparent particles weight. In the suspension, the effective stress vanishes (no contact network exists to support the particles weight) and therefore the vertical gradient of fluid pressure is expected to balance the mixture's weight of the suspension. This is exactly what is 
shown in Fig. 3. In the zone of clear fluid above the upper interface, the vertical gradient of fluid pressure is equal to the fluid's weight $\left(-\partial p_{f} / \partial z=\rho_{f} g \approx 9320 \mathrm{~kg} \mathrm{~m}^{-2} \mathrm{~s}^{-2}\right)$. In the suspension zone located between the two interfaces, the vertical gradient of fluid pressure is equal to the weight of the initial mixture $\left(-\partial p_{f} / \partial z=\rho_{\text {mix }} g \approx\right.$ $\left.9790 \mathrm{~kg} \mathrm{~m}^{-2} \mathrm{~s}^{-2}\right)$. This gradient is equal to the pure fluid's weight $\left(-\partial p_{f} / \partial z=\rho_{f} g \approx 9320 \mathrm{~kg} \mathrm{~m}^{-2} \mathrm{~s}^{-2}\right)$ below the lower interface that represents the deposited granular bed. In this layer the vertical gradient of excess pore pressure vanishes (see middle panel), i.e. it does not contribute to the force balance of the mixture, and thus the particles' weight is balanced by the effective stress term (see right panel). This dissipation of the excess pore pressure is instantaneous in the case of non-cohesive particles.

\section{Sedimentation-consolidation of estuarine mud}

\subsection{Le Havre's mud sedimentation-consolidation experiments}

Experimental data for sedimentation-consolidation of Le Havre's mud obtained with the same experimental set-up presented in the previous section are used. The mud was treated using potassium permanganate and sieved to obtain fine particles, the diameter of which is smaller than $12510^{-6} \mathrm{~m}$. The median diameter is evaluated at $d_{50}=7.510^{-6} \mathrm{~m}$. The density of dry sediment is estimated at $2590 \mathrm{~kg} \mathrm{~m}^{-3}$ by a helium pycnometer. Three initial homogeneous solid volume fractions $1.2 \%, 2.2 \%$ and $5.2 \%$ were tested and the time evolution of the solid volume fraction profiles were measured using the Proton MRI facility at the Navier Laboratory (see Pham Van Bang et al. (2008) for details).

\subsection{Closures for cohesive particles (mud)}

The heterogeneity of the suspension and the existence of electrochemical forces responsible for particle aggregation make (14) useless. A more macroscopic point of view for the drag force must be adopted. Following Toorman (1996) the Darcy-Gersevanov's semi-empirical expression for the drag force is used in the two-phase model:

$$
M_{s}^{z^{\prime}}=-M_{f}^{z^{\prime}}=\frac{\rho_{f} g}{K}\left(w_{f}-w_{s}\right)
$$

where $K$ (in $\mathrm{m} \mathrm{s}^{-1}$ ) represents the permeability. Therefore the closure issue consists in finding closure laws for the permeability $K$ and the effective stress $\sigma_{e}$. In the literature, there is a large number of formulations concerning the permeability of cohesive sediments e.g. Bartholomeeusen et al. (2000) but most of them are disconnected from the settling property of the particles. Based on the fractal theory for cohesive sediments, Merckelbach and Kranenburg (2004) have proposed formulations for the effective stress and the permeability as functions of the solid volume fraction and of the fractal dimension $n$ :

$$
K=A_{k} \alpha_{s}^{-2 /(3-n)} \quad ; \quad \sigma_{e}=A_{\sigma} \alpha_{s}^{2 /(3-n)},
$$

where $A_{k}$ and $A_{\sigma}$ are empirical coefficients to be determined from experiments. In the framework of the fractal theory, some characteristics like the floc density, $\rho_{\text {floc }}$ or the volume fraction of flocs $\phi$, amongst others, can be related to the typical floc size $d_{f l o c}$ and the fractal dimension (Winterwerp and Van Kesteren 2004):

$$
\rho_{\text {floc }}=\rho_{f}+\left(\rho_{s}-\rho_{f}\right)\left(\frac{d_{p}}{d_{\text {floc }}}\right)^{3-n} \quad ; \quad \phi=\alpha_{s}\left(\frac{d_{\text {floc }}}{d_{p}}\right)^{3-n},
$$

where $d_{p}$ represents the floc's primary particle diameter. It follows from (20) that:

$$
\rho_{\text {floc }}=\rho_{f}+\left(\rho_{s}-\rho_{f}\right) \frac{\alpha_{s}}{\phi} \quad ; \quad \phi=\alpha_{s} \frac{\rho_{s}-\rho_{f}}{\rho_{f l o c}-\rho_{f}} .
$$

When the volume fraction approaches unity, the flocs form a space filling network that corresponds to the gel point $\left(\alpha_{s}^{g e l}\right)$. 
Formulations (19) suffer two severe limitations in considering sedimentation-consolidation of mud. Knowing that $W=K \alpha_{s}\left(\rho_{s} / \rho_{f}-1\right)$ (Toorman 1996), when sediment concentration tends to zero the permeability formulation (19) gives an infinite settling velocity $W$ which should theoretically tend toward an equivalent settling velocity of a typical aggregate. Also the effective stress, given by (19), is never equal to zero, i.e. the consolidation occurs for any value of concentration. Consequently, this formulation neglects the separation between sedimentation and consolidation.

The first limitation can be overcome by using the formulation and the method proposed by Camenen and Pham Van Bang (2011). Such a formulation ensures a smooth transition of the settling velocity from the hindered settling regime to the permeability one by imposing the continuity of the first derivative of settling velocity at the gelling point. The settling velocity in the hindered regime is given by:

$$
\frac{W_{h}}{W_{0}}=\left(1-\alpha_{s}\right)^{n / 2}(1-\phi)^{n / 2-1}\left(1-\frac{\phi}{\phi_{\max }}\right)^{\phi_{\max }},
$$

where $W_{0}$ is the asymptotic settling velocity at zero concentration. It is assumed that the floc property (size and density) are fixed in space and in time, and are identical to the floc's property at the maximum floc concentration $\phi_{\max }=0.85$. As above explained this situation corresponds to the gelling fraction $\alpha_{s}^{\text {gel }}$. With the assumption of constant floc property, the floc density is given by: $\rho_{f l o c}=\rho_{f}+\left(\rho_{s}-\rho_{f}\right) \alpha_{s}^{g e l} / \phi_{\text {max }}$.

In the permeability regime, since constant floc properties are assumed between sedimentation and consolidation, the fractal dimension $n$ must be the same as in the hindered settling regime. This is achieved by seeking the solid volume fraction, at which the slopes of the settling velocity in both regimes (hindered settling and permeability) are identical. This point is denoted by $\alpha_{s}=\alpha_{s}^{\text {gel }} / \chi$ (with $\chi>1$ ). Therefore, in order to ensure the continuity of the settling velocity for both regimes, the following relationships are used:

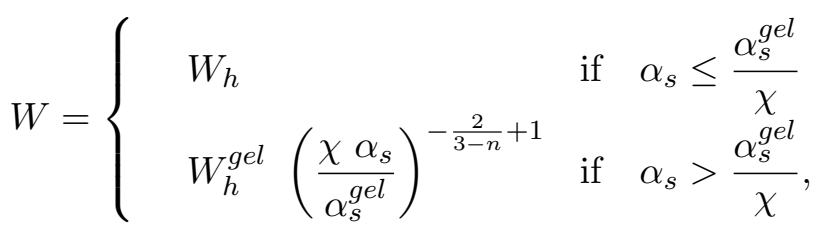

where $W_{h}^{g e l}$ corresponds to the value of $W_{h}$ at $\alpha_{s}=\alpha_{s}^{g e l} / \chi . W_{0}, n, \alpha_{s}^{g e l}$ and $\chi$ need to be determined from experiments.

In the two-phase model the permeability is used for the drag force closure (18). The relationship $K=$ $W /\left[\alpha_{s}\left(\rho_{s} / \rho_{f}-1\right)\right]$, where $W$ is calculated from $(23)$, is used in the model. The velocities of both phases are calculated from the momentum equations (12) and (13).

The effective stress represents permanent contacts between particles in concentrated suspension. The following closure is proposed:

$$
\sigma_{e}=\left\{\begin{array}{lll}
0 & \text { if } & \alpha_{s}<\alpha_{s}^{g e l} \\
\sigma_{0}\left[\left(1-\frac{\alpha_{s}-\alpha_{s}^{g e l}}{\alpha_{s}^{\text {max }}}\right)^{-\frac{2}{3-n}}-1\right] & \text { if } & \alpha_{s} \geq \alpha_{s}^{g e l} .
\end{array}\right.
$$

This formulation is asymptotically consistent with Merckelbach and Kranenburg (2004) relationship (19) and the effective stress vanishes below $\alpha_{s}^{\text {gel }}$. For this closure $\sigma_{0}$ and $\alpha_{s}^{\text {max }}$ need to be determined.

\subsection{Results and discussion}

Figure 4(a) presents the experimental and numerical settling curves. Figure 4(b) presents the experimental and numerical solid volume fraction profiles at different times for the three initial solid volume fractions $\alpha_{s}^{0}=1.2 \%$, $\alpha_{s}^{0}=2.2 \%$, and $\alpha_{s}^{0}=5.2 \%$. At first the experimental measurements are used to determine the closure's parameters $W_{0}, n, \alpha_{s}^{g e l}, \chi, \sigma_{0}$ and $\alpha_{s}^{\max }$. 
(a)
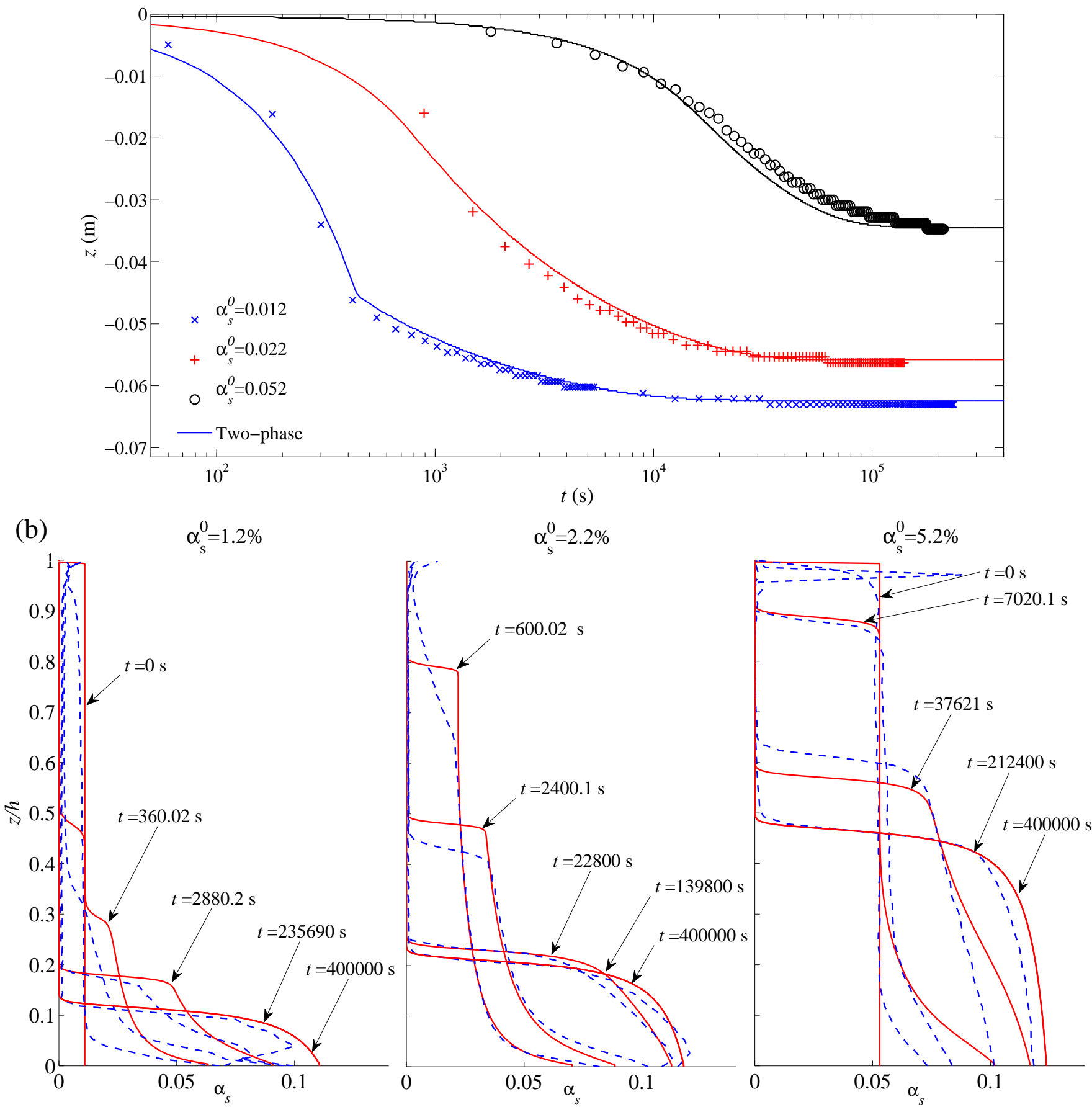

Figure 4: Comparison of two-phase model results with experiments for initial concentrations $\alpha_{s}^{0}=1.2 \%, \alpha_{s}^{0}=2.2 \%$, and $\alpha_{s}^{0}=5.2 \%$ a) Settling curves: time evolution of the mud-clear water interface position (symbols: experiments ; lines: model) and b) solid volume fraction profiles (dashed blue lines: experiments ; solid red lines: model).

For the initial solid volume fraction at $1.2 \%$, the experimental settling curve presents a slope break around 400 seconds, which represents the transition between the hindered settling regime and the permeability one i.e. the existence of a gelling point (Toorman and Berlamont 1993). This slope break is less evident for the $2.2 \%$ initial solid volume fraction and inexistent for the last case $\left(\alpha_{s}^{0}=5.2 \%\right)$, which is in consolidation since the beginning of the experiment. The value of $\alpha_{s}^{\text {gel }}$ is estimated using the method presented in Toorman (1999) and the value of the solid volume fraction at the gel point is estimated to be $\alpha_{s}^{\text {gel }} \approx 0.025$. Therefore the floc density is fixed at $\rho_{\text {floc }}=1047 \mathrm{~kg} \mathrm{~m}^{-3}$ in the model.

The closure for the permeability has been calibrated against the $1.2 \%$ initial solid volume fraction experiment following the method proposed by Camenen and Pham Van Bang (2011). The closure for the effective stress are 

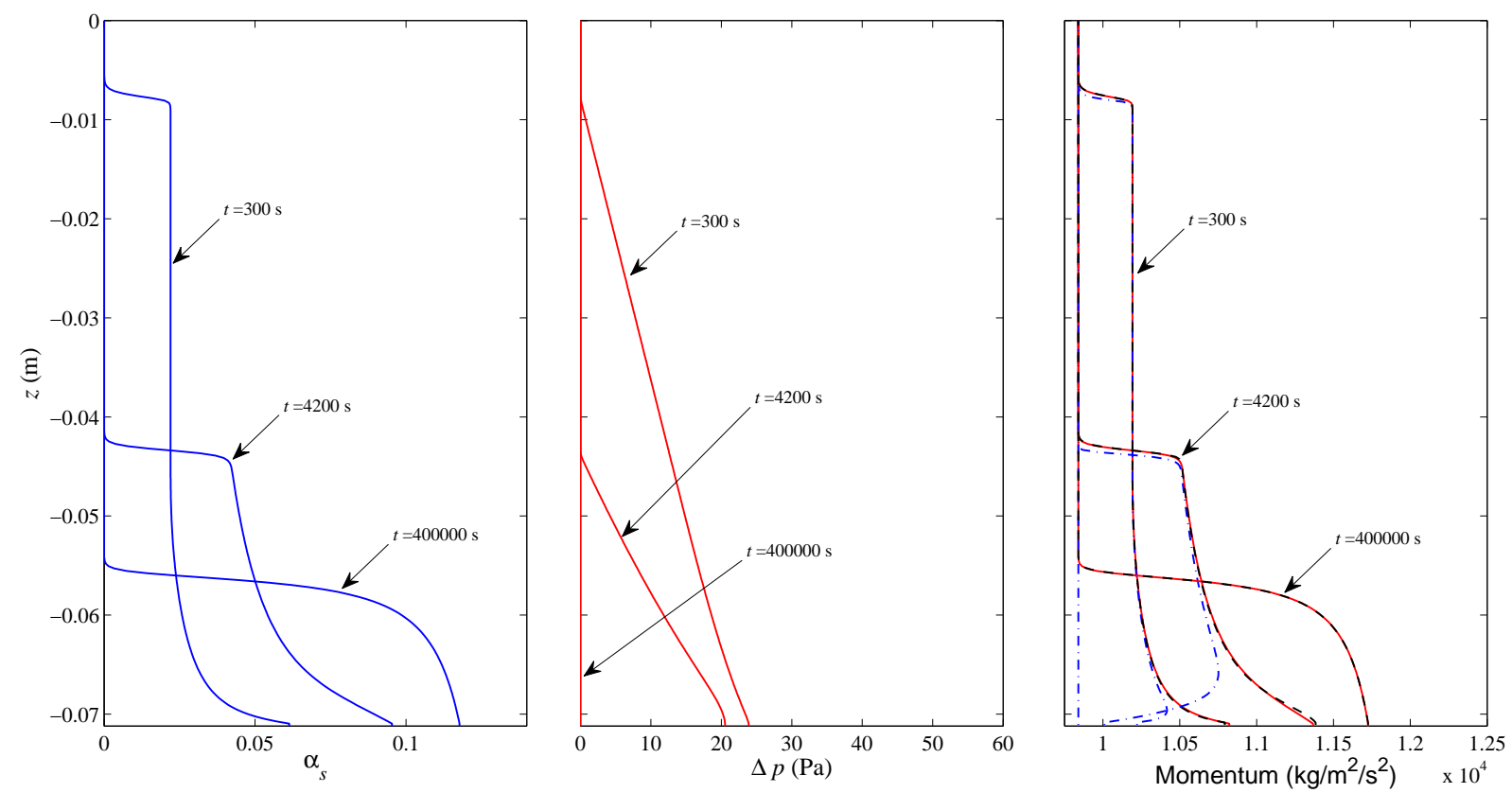

Figure 5: Vertical profiles of solid volume fraction (left panel), excess pore pressure: $\Delta p=p_{f}-\left[p_{a t m}-\rho_{f} g z\right]$ (middle panel) and mixture momentum balance (right panel) at different instants for $\alpha_{s}^{0}=0.022$. The red solid line (- - represents the gravity force, the blue dash-dotted line (-.-) represents the fluid pressure force and the dashed black line (- - ) represents the sum of the pressure and effective stress forces in equation (17).

obtained from the $5.2 \%$ initial solid volume fraction experiment following the method proposed by Been and Sills (1981). In none of the simulations presented hereafter, both the closures for the permeability and the effective stress have been simultaneously calibrated against the same experiment, and the $2.2 \%$ initial solid volume fraction experiment has not been used to calibrate the model parameters. The values of the parameters are summarised in Table 1 and the details concerning the determination of the parameter values are given in appendix $\mathrm{C}$ (see online version of the article). The value of $W_{0}=210^{-4} \mathrm{~m} \mathrm{~s}^{-1}$ corresponds to the settling velocity of an equivalent floc

Table 1: Summary of the model parameter values and their typical range.

\begin{tabular}{|c|c|c|c|c|c|c|c|}
\hline $\begin{array}{c}\text { Parameters } \\
\text { (Unit) }\end{array}$ & $\begin{array}{c}W_{0} \\
\left(\mathrm{~m} \mathrm{~s}^{-1}\right)\end{array}$ & $\begin{array}{c}n \\
(-)\end{array}$ & $\begin{array}{c}\alpha_{s}^{\text {gel }} \\
(-)\end{array}$ & $\begin{array}{c}\alpha_{s}^{\max } \\
(-)\end{array}$ & $\begin{array}{c}\sigma_{0} \\
(\mathrm{~Pa})\end{array}$ & $\begin{array}{c}\phi_{\max } \\
(-)\end{array}$ & $\begin{array}{c}\chi \\
(-)\end{array}$ \\
\hline Value & $210^{-4}$ & 2.55 & 0.025 & 0.14 & 0.14 & 0.85 & 1.283 \\
Range & $10^{-5}-10^{-3}$ & $1.7-2.8$ & $0.01-0.05$ & $0.1-0.6$ & - & $\approx 1$ & $\approx 1$ \\
\hline
\end{tabular}

diameter of $d_{f l o c}=11510^{-6} \mathrm{~m}$ with primary particles diameter of $d_{p}=210^{-6} \mathrm{~m}$ and a fractal dimension $n=2$ at low particulate Reynolds number (Winterwerp and Van Kesteren 2004). This is close to the value obtained by Van Leussen (1994) for flocs in the Ems estuary.

As in the previous case, a uniform 300-nodes mesh $\left(\Delta z=3.310^{-4} \mathrm{~m}\right)$ is used and the time step is fixed to $\Delta t=10^{-2} \mathrm{~s}$ for the numerical simulations.

In Fig. 4, as Toorman (1999) for the Oxford data, the time origin has been shifted, for the $\alpha_{s}^{0}=5.2 \%$ case, to the point where the water-sediment interface reaches a constant settlement rate. This time lag is estimated by the experimental data at 90 minutes, which is close to Toorman (1999)'s value (95 minutes). This time lag is justified by the mixing process imposed on the suspension at the beginning of each experiment. Indeed, this mixing process has induced an initial flocculation stage, for which aggregates have been formed until they reach an equilibrium state. For the two-first cases, at lower initial concentrations, the experimental time is shifted by $60 \mathrm{~s}$ for the $1.2 \%$ case and $300 \mathrm{~s}$ for the $2.2 \%$ case. This is mainly due to the time needed to introduce the 

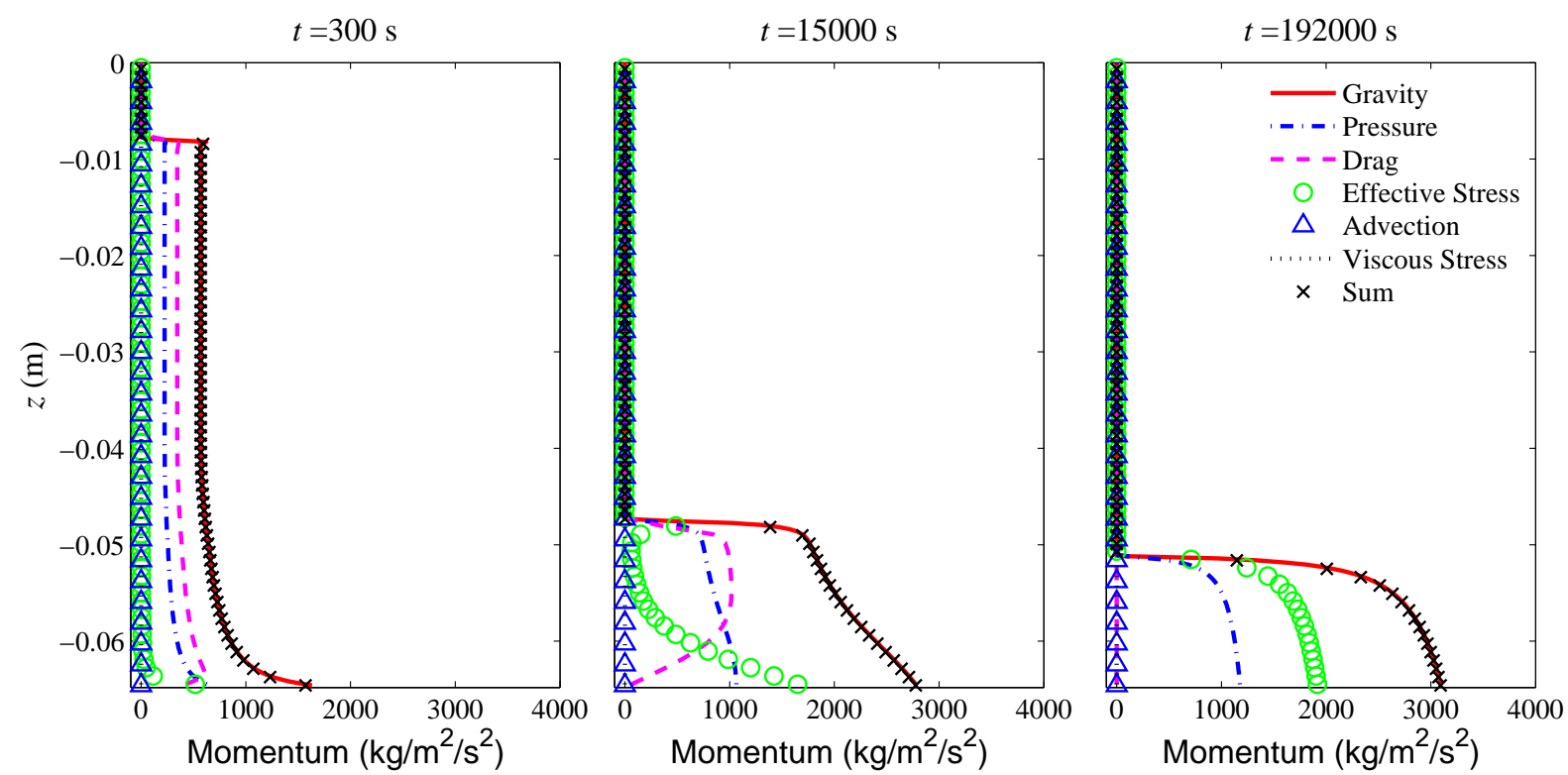

Figure 6: Vertical profiles of solid momentum balance (13) at different instants for $\alpha_{s}^{0}=0.022$. The legend is as follows: red solid line (- ${ }_{-}$gravity force ; blue dash-dotted line (-.-.) fluid pressure force ; dashed magenta line (- -) drag force ; green circles $(\circ)$ effective stress force ; blue triangles $(\triangle)$ advection force ; black dotted line $(\cdots)$ viscous stress force and black crosses $(\times)$ sum of all contributions except gravity force.

settling column in the MRI facility and to obtain the first concentration profile.

The profile of volume fraction, Fig. 4(b), continuously increases with the vertical downward even inside the cohesive bed, which is characteristic for a solid skeleton compaction, (i.e. existence of effective stresses). The best results are obtained for the first two experiments $\left(\alpha_{s}^{0}=1.2 \%\right.$ and $\left.\alpha_{s}^{0}=2.2 \%\right)$. The difference observed for the last case $\left(\alpha_{s}^{0}=5.2 \%\right)$ can be attributed to a modification of the internal structure $\left(n\right.$ and $\left.\rho_{\text {floc }}\right)$. This experiment is clearly in consolidation since the beginning, contrary to the first two. Therefore the dependency of the permeability on the sediment concentration is certainly different from the $1.2 \%$ case, for which it has been calibrated. The proposed closure laws suffer some limitations. First they depend only on the sediment concentration, which is too restrictive. As pointed out by Toorman (1999) amongst others, estuarine mud presents thixotropic behaviour such that the permeability and effective stress closures depend on the preparation of the sediment suspension (initial concentration, initial mixing, ...). Also the assumption of constant aggregate density $\left(\rho_{\text {floc }}\right)$ and fractal dimension $(n)$ in the permeability closure are a limiting assumption. Indeed, during the sedimentation-consolidation, flocculation and deflocculation processes occur and would change both the permeability and the effective stress. As reported by Chakraborti et al. (2003) the fractal dimension varies during the aggregation process. Winterwerp and Van Kesteren (2004) found that the fractal dimension is larger than 2.6 for cohesive sediment beds, whilst for suspended floc it is usually lower than 2.2. Considering constant flocs properties therefore neglects this effect and certainly constitutes the main limiting assumption of the present model. This phenomenon is not easily measurable in experiments and more refined experimental measurements are still lacking to improve our understanding of such structural changes. To the best of our knowledge, closure laws accounting for these time dependent effects have not yet been established.

Figure 5 shows successively from left to right the vertical profiles of solid volume fraction, excess pore pressure and vertical mixture momentum balance at various stages of sedimentation-consolidation (for $\alpha_{s}^{0}=2.2 \%$ ). Almost the same results for the other initial concentrations are also obtained.

The profiles of excess pore pressure (middle panel) show that the fluid pressure tends toward the pure fluid hydrostatic one at the end of the consolidation process. The greater the initial concentration is, the longer the process takes (Been and Sills 1981; Merckelbach and Kranenburg 2004). Looking at the momentum balance (right panel) one observes that during the initial stage of sedimentation, the gravity is balanced by the vertical gradient of fluid pressure everywhere, except for a thin layer near the bottom where effective stress develops. In this layer the vertical gradient of effective stress balances the apparent weight of the particles $\left(-\partial \sigma_{e} / \partial z=\alpha_{s}\left(\rho_{s}-\rho_{f}\right) g\right)$ 
and the vertical gradient of fluid pressure balances the fluid's weight only $\left(-\partial p_{f} / \partial z=\rho_{f} g \approx 9839 \mathrm{~kg} \mathrm{~m}^{-2} \mathrm{~s}^{-2}\right)$. These observations are consistent with the non-cohesive case (see Fig. 3). The difference comes from the smooth transition between the fluid pressure and the effective stress in the mixture momentum balance for the cohesive case. This difference is also noticeable on the excess pore pressure profiles, which slowly tend toward zero in the bottom layer whereas they vanish in the non-cohesive case instantaneously. The dissipation of the excess pore pressure is characteristic of the consolidation process (Been and Sills 1981). As sediment settles to the bed, the sediment concentration increases, and from mass conservation the fluid has to be expelled upward from the pores toward the fluid-sediment bed interface. This mechanism leads to an excess pore pressure induced by the fluid compression inside the pores (e.g. Toorman (1996)). As shown in Fig. 5 the proposed model allows us to represent this phenomenon. The upward Darcy flow inside the settling suspension (typically for $\alpha_{s}>\alpha_{s}^{g e l}$ ) leads to a drag increase in the solid phase that reduces its settling rate.

This is illustrated in Fig. 6 where the solid phase momentum balance is plotted (see equation 13) at different instants for the initial solid volume fraction $\alpha_{s}^{0}=2.2 \%$. At $t=300 \mathrm{~s}(\simeq 5 \mathrm{~min})$ the drag force and the buoyancy force (pressure force) are the two dominant mechanisms in the whole column, except in a very thin layer near the bottom. In this bottom layer, effective stress starts to develop as the concentration exceeds the gelling fraction $\left(\alpha_{s}^{g e l}=0.025\right.$ or $\left.\alpha_{s}^{g e l} \rho_{s} g \approx 650 \mathrm{~kg} \mathrm{~m}^{-2} \mathrm{~s}^{-2}\right)$. The suspension is in the hindered settling regime. At $t=15000 \mathrm{~s}$ $(\simeq 4 \mathrm{~h}$ ) one observes a competition between the drag force, the effective stress and the buoyancy (pressure) forces. In the upper part of the dense layer $(-0.06 \leq z \leq-0.045 \mathrm{~m})$ the drag force and the buoyancy are the dominant terms of the momentum balance. We point out that the pressure term here corresponds to the buoyancy including the effect of the excess pore pressure. This layer can be considered as a "permeability layer" because the drag force associated with strong excess pore pressure are the mechanisms controlling the suspension's settling. In the lower part of the dense layer $(-0.07 \leq z \leq-0.06 \mathrm{~m})$ the solid phase momentum balance is dominated by the effective stress and the buoyancy forces. As the effective stress is the dominant term in the momentum balance there, this layer can be denoted as "effective stress layer". At $t=192000 \mathrm{~s}(\simeq 53 \mathrm{~h})$ the drag force and the excess pore pressure have fully vanished. The equilibrium is obtained between the buoyancy and the effective stress therefore the apparent sediment's weight is balanced by its own structural compressive resistance (soil skeleton) and the consolidation process is over. This is confirmed by the flatness of the settling curve in Fig. 4(a) for $t \geq 510^{4} \mathrm{~s}$.

It is also interesting to note that Fig. 6 confirms Bürger (2000)'s dimensional analysis by showing that advection and viscous stress can be neglected in the two-phase equations for sedimentation-consolidation problems. However if one wants to look at mud-flow interactions, i.e. a suspension in sedimentation-consolidation submitted to a boundary layer flow, the viscous stress terms should be kept in the formulation and turbulence models like in Hsu et al. (2007) or Torres-Freyermuth and Hsu (2010) should be considered. This is also true for the advection term if strong horizontal variations are to be considered.

\section{Conclusion}

In this paper a vertical one-dimensional two-phase flow model is presented and has been extensively validated against high resolution experimental data (concentration profiles) for sedimentation of non-cohesive spherical particles and sedimentation-consolidation of mud. In the first case, the closure laws are the drag force around a single particle, modified by the hindrance function for the fluid-particles interaction. The particle pressure is modelled by using a hertz contact model. In the latter case, the Darcy drag expression is used to express the fluid-particles interaction and the effective stress concept is introduced instead of the hertz contact model. This stress represents the resistance of the solid skeleton to compression.

The results presented in this paper demonstrate the reliability of the proposed model and of closure laws to quantitatively reproduce the interface dynamics and the associated concentration profiles in both cases. Moreover, the vertical profile of excess pore pressure is directly calculated by the model and is consistent with experiments for both spherical particles and mud. In the cohesive case, the vertical equilibrium is more complex than in the non-cohesive one due to the formation of the solid skeleton in the sediment bed. The proposed closure laws only depend on sediment concentration and therefore neglect history effects on the aggregate structure evolution. This limitation is also shown in other classical sedimentation-consolidation models.

As claimed in the introduction of this paper, the validity of the proposed two-phase model, which covers 
from the suspension to the consolidated bed, represents a major advantage of the two-phase approach compared with the classical Kynch or Gibson ones. Two-phase approach gives a general framework that potentially allows studying more precisely the interaction between an ambient current and a sedimenting and consolidating bed. Future work will concern the use of the proposed closure laws to study mud-flow interactions in ECZs flows.

\section{Acknowledgments}

The authors thank the CETMEF (Centre d'Etude Technique Maritime Et Fluvial / French centre for marine and fluvial technical studies) for its financial support (contract $\mathrm{N}^{\circ}$ 06DSTS006). D. P.V.B. would like to thank F. Bertrand for the support during the IRM measurements at LMSGC, J.C. would like to thank Elisabeth Guazzelli, Pascale Aussillous, Yoël Forterre and Olivier Pouliquen for the fruitful discussions concerning the physics of particulate flows during his post-doc position in the GEP team (Marseille) and Hervé Michallet for his useful comments on the manuscript.

\section{Notation}

$A_{k}=$ empirical coefficients for permeability closure $\left(\mathrm{m} \mathrm{s}^{-1}\right)$

$A_{\sigma}=$ empirical coefficients for effective stress closure $\left(\mathrm{N} \mathrm{m}^{-2}\right)$

$C_{D}=$ drag coefficient (-)

$d \quad=$ particle diameter $(\mathrm{m})$

$d_{\text {floc }}=$ floc diameter $(\mathrm{m})$

$d_{p}=$ primary particle diameter $(\mathrm{m})$

$d_{50}=$ median sediment diameter $(\mathrm{m})$

$\tilde{d} \quad=$ dimensionless inter-particle distance $(-)$

$E=$ Young modulus $(\mathrm{Pa})$

$g \quad=$ gravity acceleration vector $\left(\mathrm{m} \mathrm{s}^{-2}\right)$

$K=$ permeability $\left(\mathrm{m} \mathrm{s}^{-1}\right)$

$M_{k}=$ interfacial momentum transfer vector $\left(\mathrm{kg} \mathrm{m}^{-2} \mathrm{~s}^{-2}\right)$

$n=$ fractal dimension $(-)$

$n_{R Z}=$ Richardson and Zaki's exponent $(-)$

$p_{k}=$ pressure of phase $k(\mathrm{~Pa})$

$\tilde{p} \quad=$ total pressure of the mixture $(\mathrm{Pa})$

$\mathrm{Re}_{\mathrm{p}}=$ particulate Reynolds number (-)

$u_{k}=$ velocity vector of phase $k\left(\mathrm{~m} \mathrm{~s}^{-1}\right)$

$u_{m}=$ volume averaged mixture velocity vector $\left(\mathrm{m} \mathrm{s}^{-1}\right)$

$w_{k}=$ vertical velocity of phase $k\left(\mathrm{~m} \mathrm{~s}^{-1}\right)$

$W=$ settling velocity $(\mathrm{m} / \mathrm{s})$

$W_{h}=$ settling velocity in the hindered regime $(\mathrm{m} / \mathrm{s})$

$W_{h}^{g e l}=$ settling velocity at the transition between hindered and permeability regime $\left(\mathrm{m} \mathrm{s}^{-1}\right)$

$W_{0}=$ settling velocity at zero concentration $\left(\mathrm{m} \mathrm{s}^{-1}\right)$

$Z_{i}^{u p}=$ upper interface vertical position $(\mathrm{m})$

$Z_{i}^{\text {low }}=$ lower interface vertical position $(\mathrm{m})$

Greek symbols

$\alpha_{k}=$ volume fraction of phase $k(-)$

$\alpha_{s}^{0}=$ initial solid volume fraction (-)

$\alpha_{s}^{*}=$ percolation volume fraction $(-)$

$\alpha_{s}^{\max }=$ maximum packing volume fraction $(-)$

$\alpha_{s}^{\text {gel }}=$ gel fraction $(-)$

$\beta=$ amplification factor for viscosity $(-)$ 


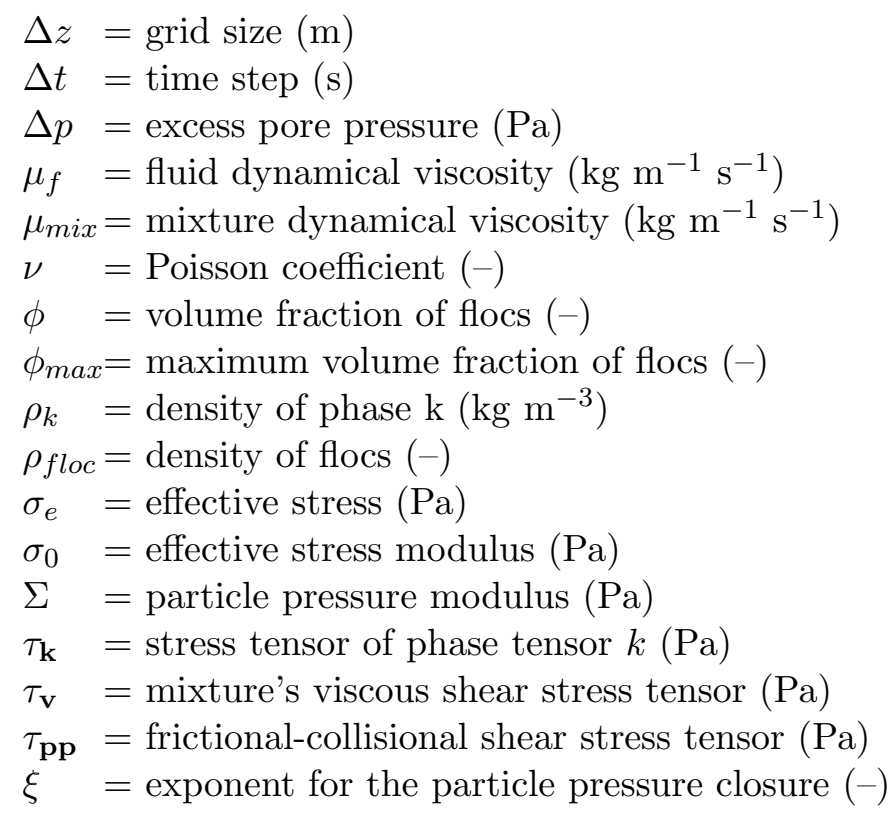

\section{References}

Bakhtyar, R., Yeganeh-Bakhtiary, A., Barry, D., Ghaheri, A. (2009). Two-phase hydrodynamic and sediment transport modeling of wave-generated sheet flow. Adv. Water Resour. 32 (8), $1267-1283$.

Barbry, N., Guillou, S., Nguyen, K. D. (2000). A two-phase approach for computing sediment transport in estuarine zones. C. R. Acad. Sci. (série II B) 328, 793-799.

Bartholomeeusen, G., Sills, G. C., Znidarcic, D., Van Kesteren, W., Merckelbach, L. M., Pyke, R., Carrier, W. K., Lin, H., Pendumadu, D., Winterwerp, H., Masala, S., Chan, D. (2000). SIDERE: numerical prediction of large-strain consolidation. Géotechnique 52, 639-648.

Been, K., Sills, G. C. (1981). Self-weight consolidation of soft soils: an experimental and theoretical study. Géotechnique 31, $519-535$.

Berzi, D., Jenkins, J. T. (2008). A theoretical analysis of free-surface flows of saturated granular-liquid mixtures. J. Fluid Mech. 608, 393-410.

Bürger, R. (2000). Phenomenological foundation and mathematical theory of sedimentation-consolidation processes. Chem. Eng. J. 80, 177-188.

Buscall, R. (1990). The sedimentation of concentrated colloidal suspensions. Colloids and surfaces 43, 33-53.

Camenen, B., Pham Van Bang, D. (2011). Modelling the settling of suspended sediments for concentrations close to the gelling concentration. Cont. Shelf Res. 31, 106-116.

Chakraborti, R., Gardner, K., Atkinson, J., Van Benschoten, J. (2003). Changes in fractal dimension during aggregation. Water Res. 37, 873-883.

Chauchat, J., Guillou, S. (2008). On turbulence closures for two-phase sediment-laden flows models. J. Geophys. Res. C11017.

Chauchat, J., Médale, M. (2010). A 3D numerical model for incompressible two-phase flow of a granular bed submitted to a laminar shearing flow, Comput. Method Appl. M. 199, 439-449.

Concha, F., Bustos, M. C., Barrientos, A. (1996). Phenomenological theory of sedimentation. In Sedimentation of Small Particles in a Viscous Fluid.Tory, E., ed, Computational Mechanics Publications, Southampton, UK, 51-96.

Dankers, P., Winterwerp, J. (2007). Hindered settling of mud flocs: Theory and validation. Cont. Shelf Res. 27 (14), 1893 1907.

Dong, P., Zhang, K. (2002). Intense near-bed sediment motions in waves and currents. Coast. Eng. 45 (2), 75 - 87.

Drew, D. A. (1983). Mathematical modelling of two-phase flow. J. Appl. Mech. 15, 261-291.

Drew, D. A., Lahey, R. T. (1993). Analytical modelling of multiphase-flow. In Particulate two-phase flows series on chemical engineering. Rocco, ed. Butterworth-Heinemann, Boston, USA, 509 - 566 .

Einstein, A. (1906). Eine neue bestimmung der molekuldimensionen. An. Phys. 19, $289-306$.

Frankel, N. A., Acrivos, A. (1967). On the viscosity of a concentrated suspension of solid spheres. Chem. Eng. Sci. 22, 847-853.

Gibson, R. E., Englund, G. L., Hussey, M. J. L. (1967). The theory of one-dimensional consolidation of saturated clays. Géotechnique 17, $261-273$. 
Graham, A. L. (1981). On the viscosity of suspensions of solide spheres. Applied Science Research $37,275-286$.

Greimann, B., Holly, F. (2001). Two-phase flow analysis of concentration profile. J. Hydraulic. Eng. $127,753-761$.

Greimann, B. P., Muste, M., Jr., F. M. H. (1999). Two-phase formulation of suspended sediment transport. J. Hydraul. Res. $37,479-500$

Hsu, T., Jenkins, J. T., Liu, L. F. (2003). On two-phase sediment transport: Dilute flow. J. Geophys. Res. $108,14$.

Hsu, T.-J., Jenkins, J. T., Liu, P. L.-F. (2004). On two-phase sediment transport: sheet flow of massive particles. P. Royal Soc. A-Math. Phy. 460 (2048), 2223-2250.

Hsu, T. J., Traykovski, P. A., Kineke, G. C. (2007). On modeling boundary layer and gravity-driven fluid mud transport. J. Geophys. Res. 112 (C4).

Jackson, R. (2000). The dynamics of fluidized particles. Cambridge University Press, Cambridge.

Jha, S. K., Bombardelli, F. A. (2010). Toward two-phase flow modeling of nondilute sediment transport in open channels. J. Geophys. Res. 115 (F3).

Jiang, J., Law, A. W.-K., Cheng, N.-S. (2004). Two-phase modeling of suspended sediment distribution in open channel flows. J. Hydraulic Res. 42, $273-281$.

Kynch, G. (1952). A theory of sedimentation. T. Faraday Soc. 48, 166-176.

Le Hir, P. (1994). Fluid and sediment "integrated" modelling application to fluid mud flows in estuaries. 4th Nearshore and Estuarine Cohesive Sediment Tranport Conference, Intercoh'94, Wallingford. John Wiley \& Sons, Chichester, 417-428.

Longo, S. (2005). Two-phase flow modeling of sediment motion in sheet-flows above plane beds. J. Hydraulic. Eng. 131 (5), $366-379$

Merckelbach, L. M., Kranenburg, C. (2004). Determining effective stress and permeability equations for soft mud from simple laboratory experiments. Géotechnique 54, 581-591.

Nguyen, K. D., Guillou, S., Chauchat, J., Barbry, N. (2009). A two-phase numerical model for suspended-sediment transport in estuaries. Adv. Water Resour. 32 (8), $1187-1196$.

Nguyen, D. H., Levy, F., Bang, D. P. V., Guillou, S., Nguyen, K. D., Chauchat, J. (2012). Simulation of dredged sediment releases into homogeneous water using a two-phase model. Adv. Water Resour. 48 (0), 102-112.

Nicolai, H., Herzhaft, B., Hinch, E. J., Oger, L., Guazzelli, E. (1995). Particle velocity fluctuations and hydrodynamic self-diffusion of sedimenting non-brownian spheres. Phys. Fluids 7 (12).

Pham Van Bang, D., Lefrançois, E., Sergent, P., Bertrand, F. (2008). MRI experimental and finite elements modelling of the sedimentation-consolidation of mud. La Houille Blanche 3, 39-44.

Richardson, J. F., Zaki, W. N. (1954). Sedimentation and fluidization: Part i. Trans. Instn. Chem. Engrs 32.

Teisson, C. (1991). Cohesive suspended sediment transport: feasibility and limitations of numerical modeling. J. Hydraulic Res. 29 (6), 755-769.

Teisson, C., Simonin, O., Galland, J. C., Laurence, D. (1992). Turbulence and mud sedimentation: A reynolds stress model and a two-phase flow model. In: Proceedings of 23rd International Conference on Coastal Engineering. ASCE, 2853-2866.

Terzaghi, K. (1923). Die Berechnung der Durchlassigkeitsziffer des Tones aus dem Verlauf der hydrodynamischen Spannungerscheinungen. Sitz. Akad. Wissen. Wien, Math. Naturwiss. Kl., Abt. IIa. 132, 125-138.

Thiébot, J., Guillou, S., Brun-Cottan, J.-C. (2011). An optimisation method for determining permeability and effective stress relationships of consolidating cohesive sediment deposits. Cont. Shelf Res. 31, S117-S123.

Toorman, E. A. (1996). Sedimentation and self-weight consolidation: general unifying theory. Géotechnique 46, $103-113$.

Toorman, E. A. (1999). Sedimentation and self-weight consolidation: constitutive equations and numerical modelling. Géotechnique 49, 709-726.

Toorman, E. A., Berlamont, J. E. (1993). Mathematical modeling of cohesive sediment settling and consolidation. Nearshore and Estuarine Cohesive Sediment Transport, Coastal Estuarine Studies, Vol. 42. AGU, Washington, DC, $167-184$.

Torres-Freyermuth, A., Hsu, T.-J. (2010). On the dynamics of wave-mud interaction: A numerical study. J. Geophys. Res. $115(\mathrm{C} 7)$.

Van Leussen, W. (1994). Estuarine macroflocs and their role in fine-grained sediment transport. Ph.D. thesis, University of Utrecht, The Netherlands.

Winterwerp, J., Van Kesteren, W. (2004). Introduction to the Physics of Cohesive Sediment Dynamics in the Marine Environment. Elsevier, Amsterdam. 